\title{
Pan-PPAR Modulation Effectively Protects APP/PS1 Mice from Amyloid Deposition and Cognitive Deficits
}

\author{
Markus P. Kummer • Rafael Schwarzenberger • \\ Sakina Sayah-Jeanne - Mathieu Dubernet • Robert Walczak • \\ Dean W. Hum • Stephanie Schwartz • Daisy Axt • Michael T. Heneka
}

Received: 5 March 2014 / Accepted: 5 May 2014 /Published online: 17 May 2014

(C) The Author(s) 2014. This article is published with open access at Springerlink.com

\begin{abstract}
Alzheimer's disease (AD) is a neurodegenerative condition that leads to neuronal death and memory dysfunction. In the past, specific peroxisome proliferator-activated receptor (PPAR) $\gamma$-agonists, such as pioglitazone, have been tested with limited success to improve AD pathology. Here, we investigated the therapeutic efficacy of GFT1803, a novel potent PPAR agonist that activates all the three PPAR isoforms $(\alpha / \delta / \gamma)$ in the APP/PS1 mouse model in comparison to the selective PPAR $\gamma$-agonist pioglitazone. Both compounds showed similar brain/plasma partitioning ratios, although whole body and brain exposure to GFT1803 was significantly lower as compared to pioglitazone, at doses used in this study. Oral treatment of APP/PS1 mice with GFT1803 decreased microglial activation, amyloid $\beta(\mathrm{A} \beta)$ plaque area, $\mathrm{A} \beta$ levels in sodium dodecyl sulfate- and formic acid-soluble fractions in a concentration-dependent manner. With a single exception of $A \beta 38$ and $A \beta 40$ levels, measured by ELISA, these effects were not observed in mice treated with pioglitazone. Both ligands decreased glial fibrillary acidic protein (GFAP) expression to similar extent and did not affect ApoE expression. Finally, GFT1803 increased insulin-degrading enzyme expression. Analysis of spatial memory formation in the Morris water maze demonstrated that both compounds were able to partially revert the phenotype of APP/PS1 mice in comparison to wild-type mice with GFT1803 being most effective. As
\end{abstract}

M. P. Kummer · R. Schwarzenberger · S. Schwartz $\cdot$ D. Axt $\cdot$

M. T. Heneka $(\bowtie)$

Clinical Neuroscience Unit, Department of Neurology, University

of Bonn, Sigmund-Freud-Strasse 25, 53127 Bonn, Germany

e-mail: michael.heneka@ukb.uni-bonn.de

S. Sayah-Jeanne $\cdot$ M. Dubernet $\cdot$ R. Walczak $\cdot$ D. W. Hum Genfit, Parc Eurasante, 885 av. Eugène Avinée, 59120 Loos, France

M. T. Heneka

German Center for Neurodegenerative Diseases,

Ludwig-Erhard-Allee 2, 53175 Bonn, Germany compared to pioglitazone, GFT1803 (pan-PPAR agonist) produced both quantitatively superior and qualitatively different therapeutic effects with respect to amyloid plaque burden, insoluble $A \beta$ content, and neuroinflammation at significantly lower whole body and brain exposure rates.

Keywords Alzheimer · PPAR · Inflammation · Amyloid . Behavior
Abbreviations
NFkB Nuclear factor kappa-light-chain-enhancer
STAT Signal transducer and activator of transcription-1
FA Formic acid
SDS Sodium dodecylsulfate

\section{Introduction}

Alzheimer's disease is clinically characterized by progressive memory loss and decline of cognitive functions. Besides the classical histopathological hallmarks, extracellular amyloid $\beta$ $(\mathrm{A} \beta)$ deposition and neurofibrillary tangles of tau protein, neuroinflammation has been established as a major component [1]. $\mathrm{A} \beta$ derives from a larger precursor protein (APP) by subsequent cleavages by two aspartyl proteases, [beta]-site APP cleaving enzyme 1 (BACE1) and $\gamma$-secretase, resulting in the secretion of $A \beta$ into the brain parenchyma [1]. Deposition of $\mathrm{A} \beta$ has been suggested to initiate the pathological sequalae which ultimately leads to the development of Alzheimer's disease (AD) [2]. Additionally, oligomeric, soluble $A \beta$ causes cellular toxicity and interferes with memory formation at the synapse thereby causing the observed memory loss $[3,4]$. Therefore, strategies that interfere with the formation and deposition of $A \beta$ or accelerate its removal hold therapeutic promise. 
Although there is currently no curative treatment for $\mathrm{AD}$ patients, a number of epidemiological studies demonstrated that a sustained intake of several non-steroidal antiinflammatory drugs (NSAIDs) reduces AD risk by as much as $80 \%$ and delays its onset [5]. NSAIDs are mostly known as cyclooxygenase inhibitors, preventing prostaglandin and thromboxane synthesis from arachidonic acid, but additional cyclooxygenase-unrelated activities, such as binding to prostaglandin receptors, modulation of $\gamma$-secretase activity and activation of the peroxisomal proliferator receptor $\gamma$ (PPAR $\gamma$ ), a member of the nuclear hormone receptor superfamily, seem to be involved in $\mathrm{AD}$ prevention. Regarding the latter, it was rapidly suggested that protective effects arise from the ability of NSAIDs to ligate PPAR $\gamma$ and to inhibit neuroinflammation in the $\mathrm{AD}$ brain [6]. Of note, among different NSAIDs, indomethacin and ibuprofen were characterized as PPAR $\gamma$ agonists with anti-inflammatory properties [7]. PPAR $\gamma$ is expressed in cells of the myeloid lineage including macrophages and microglia and its activation inhibits nuclear factor kappa-light-chain-enhancer (NFKB), AP-1, and STAT-1dependent signal transduction pathways, thereby suppressing key inflammatory cytokines, such as TNF- $\alpha$, IL-1 $1 \beta$, and Il-6 $[8,9]$.

The development of more specific ligands of PPAR $\gamma$, namely the thiazolidinedione (TZD) class of oral antidiabetics has prompted experimental studies to further validate PPAR $\gamma$ mediated neuroprotection in models of cerebral ischemia, Parkinson's disease (PD), amyotrophic lateral sclerosis, and $\mathrm{AD}$ [10]. A preventive effect of the TZD pioglitazone on sodium dodecylsulfate (SDS)-soluble A $\beta 40$ accumulation [11] as well as on micro- and astroglial activation and $A \beta$ plaque burden [12] was shown in two different murine $A D$ models, Tg2576 mice and APPV717I mice, respectively. Besides the $A \beta$-lowering effect, PPAR agonists have also been shown to suppress $A \beta$-mediated activation of microglia and prevented cortical or hippocampal neuronal cell death in vitro [13-15]. Mechanistically, PPAR $\gamma$ has been shown to affect $A \beta$ metabolism by suppressing the immunostimulated BACE1 promoter via a PPAR response element $[16,17]$ thereby lowering BACE1 protein levels and, as a consequence, $\mathrm{A} \beta$ production.

Due to a number of side effects and adverse clinical observations, TZDs of the pioglitazone generation recently came under scrutiny, followed by the development of a further class of PPAR agonists, which activate not only PPAR $\gamma$ but also the two other isoforms, PPAR $\alpha$ and PPAR $\delta$. The use of those pan-PPAR agonists is appealing since it has been reported that, in contrast to PPAR $\gamma$, the expression of PPAR $\alpha$ and PPAR $\delta$ is reduced in AD brains [18]. PPAR $\alpha$ function insufficiency may predispose neural tissue and cerebral microvasculature to exacerbated oxidative stress, since PPAR $\alpha$ activation by fenofibrate and other agonists attenuates vascular damage through inhibition of lipotoxicity, inflammation, and reactive oxygen species [19]. Likewise, PPAR $\delta$ was examined for possible neuroprotective effects. Using synthetic PPAR $\delta$ specific agonists neuroprotective effects have been observed in animal models of cerebral ischemia, multiple sclerosis, AD, $\mathrm{PD}$, radiation-induced brain injury, and spinal cord injury [20-24].

In this study, we investigated the efficacy of GFT1803, a novel, experimental pan-PPAR agonist on amyloid burden, spatial memory formation, and neuroinflammation in the APP/PS1 mouse model.

\section{Material and Methods}

Animals

Age-matched, female APP/PS1 transgenic animals (\# 005864 , The Jackson Laboratory) [25] were on C57/B16 genetic background. Mice were mice fed on a normal mouse chow or on chow containing either 1 or $10 \mathrm{mg} / \mathrm{kg}$ GFT1803 or $50 \mathrm{mg} / \mathrm{kg}$ pioglitazone from 4 to 6 months of age. Mice numbers were $n=12$ for 1 and $10 \mathrm{mg} / \mathrm{kg}$ GFT1803, $n=11$ for APP/PS1, and $n=10$ for $50 \mathrm{mg} / \mathrm{kg}$ pioglitazone. For pharmacokinetic studies, Swiss mice (Elevage Janvier, France) were used. Mice were housed under standard conditions at $22{ }^{\circ} \mathrm{C}$ and a 12-h lightdark cycle with free access to food and water. Animal care and handling was performed according to the declaration of Helsinki and approved by the local ethical committees.

\section{Gal4-PPAR Activation Assays}

COS-7 cells were maintained in standard culture conditions (Dulbecco's modified Eagle's minimal medium (DMEM)) supplemented with $10 \%$ fetal calf serum, $1 \%$ sodium pyruvate, $1 \%$ essential amino acids, and $1 \%$ streptomycin/ penicillin at $37{ }^{\circ} \mathrm{C}$ in a humidified atmosphere of $5 \% \mathrm{CO}_{2}$. All tested compounds were dissolved in DMSO (SigmaAldrich). Cells were transfected using $2 \mu 1$ JetPEITM (Polyplus transfection) $/ \mu \mathrm{g}$ of DNA. Briefly, $40 \mu \mathrm{g}$ of DNA was transfected in a $225-\mathrm{cm}^{2}$ culture flask of adherent COS-7 cells (respecting the 1:50 ratio between the Gal4(RE)_TkpGL3 plasmid and the plasmid coding the nuclear receptor of interest (pGal4-hPPAR $\alpha$, pGal4hPPAR $\gamma$, pGal4-hPPAR $\delta$, pal4-mPPAR $\alpha$, pGal4mPPAR $\gamma$, and pGal4-mPPAR $\delta$ ) or of the pGal4phi plasmid (negative control). Cells were seeded in 384-well plates at the density of 20,000 cells/well and then incubated for $4 \mathrm{~h}$ at $37{ }^{\circ} \mathrm{C}$. The activation was performed by using the Genesis Freedom $200^{\mathrm{TM}}$ robotic unit (Tecan), in fresh medium supplemented with $2 \%$ of synthetic serum, free of lipids (Ultroser $^{\mathrm{TM}}$, Biosepra) supplemented with the tested compounds (compound of interest or reference molecules) or vehicle (DMSO $0.1 \%$ ). Luciferase activity was measured 
using the Steady-Glo Luciferase Assay System (Promega, Madison, WI, USA). All transactivation experiments were performed at least two times. Activation curves were realized using SigmaPlot (version 7.0 from SPSS, IBM) software. SigmaPlot was also used to fit the standard curves and then determine the specific $\mathrm{EC}_{50}$ values, maximum effect versus reference molecules and Hill slope. The $E_{\max }$ effect of GFT1803 was calculated relative to the maximal induction (plateau) obtained with the corresponding reference compound. The reference compounds for PPAR $\alpha, \operatorname{PPAR} \gamma$, and PPAR $\delta$ were fenofibrate $(100 \mu \mathrm{M})$, rosiglitazone $(10 \mu \mathrm{M})$, and GW501516 $(1 \mu \mathrm{M})$, respectively.

Compound Pharmacokinetics Study in Mice

The compound was administered to 5-week-old, male Swiss mice (Elevage Janvier, France) by the PO route in a solution of $0.5 \%$ methyl cellulose (Sigma-Aldrich; M0262) and $0.3 \%$ Polysorbate 80 (Tween 80; Sigma-Aldrich P8074). At the precise time point, blood samplings were done at the retro-orbital sinus. Blood samples were collected into tubes containing both lithium and heparin, centrifuged at $2,500 \mathrm{rpm}$ at $4{ }^{\circ} \mathrm{C}$, and plasma was collected. Individual plasma aliquots were frozen at $-20^{\circ} \mathrm{C}\left( \pm 5^{\circ} \mathrm{C}\right)$ and stored until analysis.

Animals were perfused with $7 \mathrm{ml}$ cold saline; the brain tissue was collected and frozen at $-20^{\circ} \mathrm{C}$. The molecular and daughter ions were selected for each molecule by direct infusion into the MS-MS system. According to the expected sensitivity, eight-point calibration standards $(1,5,10,50$, $100,500,1,000$, and $5,000 \mathrm{ng} / \mathrm{ml}$ ) were run using standard conditions which consist to liquid chromatography-tandem mass spectrometry (LC-MS/MS) system with C18 column after precipitation of the plasma proteins with acetonitrile before the start of the analytical test. Calibration standards were performed in each matrix (plasma and brain). Prior to analysis, $100 \mu \mathrm{l}$ of each plasma sample was mixed with $300 \mu \mathrm{l}$ acetonitrile. Following protein precipitation, samples were vortex mixed for $30 \mathrm{~s}$, centrifuged for $5 \mathrm{~min}$ at 15,000 rpm and the supernatant was removed. Analysis was performed using LC/MS/MS determination according to previous analytical test results. Brains were homogenized with a potter using water $(1: 1,(w / w))$. Homogenate $(100 \mu \mathrm{l})$ was mixed with $100 \mu \mathrm{l}$ of acetonitrile. The mixture was vortexed for $30 \mathrm{~s}$ and centrifuged for $5 \mathrm{~min}$ at 15,000 rpm. Brain homogenate supernatants were directly measured by LC/MS/MS using a C18 Kromasil column and API4000 (Applied Biosystem) or Quattro (Waters) mass spectrometer.

\section{Brain Protein Extraction}

Snap-frozen brain hemispheres were extracted as previously described [26]. In addition, the SDS-insoluble pellet was extracted with $70 \%$ formic acid in water. Formic acid was removed using a speed vac (Eppendorf), and the resulting pellet was solubilized in $200 \mathrm{mM}$ Tris- $\mathrm{HCl}$, $\mathrm{pH}$ 7.5.

\section{Tissue Preparation}

After competition of the behavioral testing, mice were anesthetized using isoflurane and transcardially perfused with $15 \mathrm{ml}$ phosphate-buffered saline. The brains were removed from the skull. One hemisphere was immediately deep-frozen for biochemical analysis, and the other was fixed in $4 \%$ paraformaldehyde.

\section{ELISA}

Quantitative determination of $A \beta$ was performed using an electrochemiluminescence ELISA for $A \beta_{1-38}, A \beta_{1-40}$, and $A \beta_{1-42}$ (Mesoscale). Samples SDS and formic acid (FA) fractions were at east 20 times diluted in $1 \% \mathrm{Tx}-100,25 \mathrm{mM}$ Tris- $\mathrm{HCl} \mathrm{pH}$ 7.5, $150 \mathrm{mM} \mathrm{NaCl}$.

\section{Histology}

Serial sagittal cryosections ( $40 \mu \mathrm{m}$, four sections per mouse) were immunostained using antiserum against glial fibrillary acidic protein (GFAP) (DAKO, 1:800), antibody IC16 [27] against human $\mathrm{A} \beta 1-15$ (1:400), and rabbit polyclonal antiserum against Ibal (WAKO, 1:200). For that, sections were treated $15 \mathrm{~min}$ at $80^{\circ} \mathrm{C}$ in $100 \mathrm{mM}$ citrate buffer $\mathrm{pH} 5.5$ and afterwards with $50 \%$ methanol for $10 \mathrm{~min}$. Sections were washed in phosphate-buffered saline (PBS), permeabilized using PBST (PBST, $0.1 \%$ Tx-100), and blocked for $1 \mathrm{~h}$ in $20 \%$ goat serum in PBST. Primary antibodies were added in $20 \%$ goat serum on PBST for $18 \mathrm{~h}$ at $4{ }^{\circ} \mathrm{C}$ while gently rocking. Secondary antibodies were added in $20 \%$ goat serum on PBST for $1.5 \mathrm{~h}$ at RT. Sections were mounted with ImmuMount (Thermo Scientific, Bonn, Germany) on Superfrost slides.

For methoxy-XO4 [28] staining, sections were rinsed in PBS, incubated in $10 \mu \mathrm{M}$ methoxy-XO4 in $40 \%$ ethanol/ $60 \% \mathrm{H}_{2} \mathrm{O}$ adjusted to $\mathrm{pH} 10$ with $0.1 \mathrm{~N} \mathrm{NaOH}$ for 10 min at RT, washed three times with water, incubated for $2 \mathrm{~min}$ in $0.2 \% \mathrm{NaOH}$ in $80 \%$ ethanol, and washed three times with water. Sections were analyzed using a BX61 microscope equipped with a disk scanning unit to achieve confocality (Olympus, Hamburg, Germany). Image stacks were deconvoluted using Cell ${ }^{\wedge} \mathrm{P}$ (Olympus, Hamburg, Germany). Quantitative assessment of plaque areas was done using the MBF-ImageJ $1.43 \mathrm{~m}$ software bundle (NIH, Bethesda, MA, USA). 


\section{Protein Blotting}

Samples were separated by 4-12\% NuPAGE (Invitrogen) using MES or MOPS buffer and transferred to nitrocellulose membranes. APP, APP C-terminal fragments (CTF), and A $\beta$ were detected using antibody $6 \mathrm{E} 10$ (Covance) and the Cterminal APP antibody 140 (CT15) [29], IDE using antibody PC730 (Calbiochem), GFAP using anti-GFAP antiserum Z0334 (Dako), ApoE using antibody sc-6384 (Sant Cruz), and tubulin using antibody E7 (Developmental Studies Hybridoma Bank). For dot blot analysis, $10 \mu \mathrm{l}$ samples containing $25 \mu \mathrm{M}$ peptide were mixed with $200 \mu \mathrm{l}$ PBS and transferred to nitrocellulose membranes. Immunoreactivity was detected by enhanced chemiluminescence reaction (Millipore), and luminescence intensities were analyzed using Chemidoc XRS documentation system (Biorad).

\section{Open Field Behavior}

The open field consisted of a $61 \times 61 \times 61 \mathrm{~cm}$ Perspex box with dark walls and a white floor and was dimly illuminated. The open field was virtually divided into corridors along the walls (10 cm wide), corners $(10 \times 10 \mathrm{~cm})$, and a center $(40 \times 40 \mathrm{~cm})$. Mice were put in the middle of the open field. The mice were tracked for 5 min on three subsequent days using Ethovision software (Noldus, Wageningen, The Netherlands).

\section{Morris Water Maze}

The Morris water maze used consisted of a 61-cm high plastic circular basin (diameter $1 \mathrm{~m}$ ) approximately half-filled with water, with an invisible platform of $10 \times 10 \mathrm{~cm}$ just under water in the middle of one of four equal virtual segments (quadrants). A white curtain surrounded the basin. Three asymmetrically applied intra-maze cues were presented to the animals. The water was made opaque using white dispersion color. The mice were subjected to one training session per day for eight consecutive days. One training session consisted of four trials of $40 \mathrm{~s}$ each. Time between trials was $10 \mathrm{~s}$. The starting position in each trial was quasi-random. If a mouse did not succeed, it was put onto the platform for $15 \mathrm{~s}$. On day 9 , mice were put in the basin in the absence of the platform and the time spend in the quadrants was determined (probe trial). Mice were tracked using Ethovision software (Noldus, Wageningen, The Netherlands).

\section{Data Analysis}

Results were expressed as mean \pm SEM of at least three experiments. For normally distributed samples, Student's $t$ test was used for single comparisons of means and one-way ANOVA for multiple comparisons of means combined with the Tukey post test to evaluate statistical significance. The levels for statistical significance were $* p<0.05$, $* * p<0.01$, and $* * * p<0.001$. All evaluations were conducted using Prism 5.03 (Graphpad, San Diego, CA, USA).

\section{Results}

GFT1803 is a Potent and Equilibrated Pan-PPAR Compound with a Significant Brain Penetration

GFT1803 is a diphenyl propane derivative and was designed to activate all mouse and human PPAR isoforms $(\alpha, \delta$, and $\gamma)$ with comparable affinities and with moderate efficacy, as compared to classical PPAR reference agonists, i.e., fenofibrate, rosiglitazone, and GW501516. As shown in Table 1, PPAR $\alpha /$ $\delta / \gamma$ activation profile of GFT1803 is equilibrated in terms of $\mathrm{EC}_{50}$ values (10-70 $\left.\mathrm{nM}\right)$. The maximal efficacy for each of PPAR isoform $\left(\mathrm{E}_{\max }\right)$ is in the range of 57 to $84 \%$ of the $\mathrm{E}_{\max }$ value of the corresponding reference compound.

GFT1803 was also optimized to provide a significant central exposure upon oral administration. The central pharmacokinetic profile of GFT1803 at two different doses was established in the Swiss mice model and compared to that of pioglitazone (Fig. 1b, c). The central exposure of pioglitazone (30 mg/kg) was 3.57 times higher as compared to GFT1803 $(10 \mathrm{mg} / \mathrm{kg})$ and 50 times higher as compared to GFT1803 (1 mg/kg) (Fig. 1b, Table 2). However, both compounds showed similar brain/plasma partitioning ratio of $0.27-0.35$ (Table 2).

\section{GFT1803 Reduces A $\beta$ Deposition and Neuroinflammation} in APP/PS1 Mice

To test the efficacy of GFT1803 on amyloid pathology in an AD mouse model, we treated APP/PS1 mice for a period of 8 weeks, starting at the age of 4 months (Fig. 1a). GFT1803 and pioglitazone were both included in regular chow pellets to yield daily drug regimens of $1 \mathrm{mg} / \mathrm{kg}$ (GFT1803), $10 \mathrm{mg} / \mathrm{kg}$ (GFT1803), and $50 \mathrm{mg} / \mathrm{kg}$ (pioglitazone), with respect to an average daily food intake rate.

We differentiated the pools of $A \beta$ in the forebrain by sequential extraction of brain homogenates starting with radioimmunoprecipitation assay buffer (RIPA), followed by $2 \%$ SDS and finally by $70 \%$ formic acid. Fractions were analyzed by multiplex ELISA for $\mathrm{A} \beta 38, \mathrm{~A} \beta 40$, and $\mathrm{A} \beta 42$. We observed no effect of drug treatments on $A \beta 40$ and 42 species in the RIPA-soluble fractions (Fig. 1d). A $\beta 38$ concentrations were below the detection limit. In the SDS-soluble fractions, treatment with GFT1803 $(10 \mathrm{mg} / \mathrm{kg})$ resulted in a modest but significant decrease of both $A \beta 38$ and $A \beta 40$ species (Fig. 1e). Pioglitazone showed no effect on $A \beta$ in both RIPA and SDS-soluble fractions. Finally, the analysis of the most insoluble $A \beta$ pool after formic acid extraction 
Table 1 Transactivation assays in COS-7 cells

\begin{tabular}{|c|c|c|c|c|c|c|}
\hline & \multicolumn{2}{|c|}{ Gal4-PPAR $\alpha$ (LBD) } & \multicolumn{2}{|c|}{ Gal4-PPAR $\gamma(\mathrm{LBD})$} & \multicolumn{2}{|c|}{ Gal4-PPAR $\delta$ (LBD) } \\
\hline & $\mathrm{EC}_{50}(\mu \mathrm{M})$ & TOP (\% ref $)$ & $\mathrm{EC}_{50}(\mu \mathrm{M})$ & TOP (\% ref) & $\mathrm{EC}_{50}(\mu \mathrm{M})$ & TOP (\% ref) \\
\hline Murine & 0.02 & 78 & 0.01 & 65 & 0.01 & 84 \\
\hline Human & 0.03 & 57 & 0.06 & 61 & 0.07 & 84 \\
\hline
\end{tabular}

Transactivation assays were performed in COS-7 cells. The E $_{\max }$ effect of GFT1803 is calculated relative to the maximal induction obtained with the corresponding reference compound in the same experiment. The reference compounds for PPAR $\alpha$, PPAR $\gamma$, and PPAR $\delta$ were fenofibrate (100 $\mu \mathrm{M})$, rosiglitazone $(10 \mu \mathrm{M})$, and GW501516 $(1 \mu \mathrm{M})$, respectively

(Fig. 1f) revealed a strong and dose-dependent reduction for all three A $\beta$ peptides in mice treated with GFT1803 (1 and $10 \mathrm{mg} / \mathrm{kg})$. Treatment with pioglitazone $(50 \mathrm{mg} / \mathrm{kg})$ reduced both $A \beta 38$ and $A \beta 40$ in formic acid-soluble fractions with efficacy comparable to that of GFT1803 at $1 \mathrm{mg} / \mathrm{kg}$, but had no statistically significant effect on $A \beta 42$.

Further, we analyzed brain sections stained with the amyloid dye, methoxy-XO4 and by immunostaining for $\mathrm{A} \beta$ (IC16 antibody) and for the microglial marker Ibal. $A \beta$ deposits were smaller and Iba1-immunoreactivity was decreased in sections from GFT1803 treated mice (Fig. 2a). Quantification of methoxy-XO4-positive plaques in samples from mice treated with GFT1803 $(10 \mathrm{mg} / \mathrm{kg})$ revealed a reduction of $48.5 \%$ in the cortex and a reduction of $32 \%$ in the hippocampus (Fig. 2b, c). However, no effect was observed for mice treated with either pioglitazone or with GFT1803 at $1 \mathrm{mg} / \mathrm{kg}$. Determination of the $A \beta$-covered area by immunohistochemistry showed that GFT1803 (both doses) strongly reduced the A $\beta$ load in the cortex ( $34 \%$ for $1 \mathrm{mg} / \mathrm{kg}$ and $42 \%$ for $10 \mathrm{mg} / \mathrm{kg}$ ) and hippocampus (20\% for $1 \mathrm{mg} / \mathrm{kg}$ and $39 \%$ for $10 \mathrm{mg} / \mathrm{kg}$ ) (Fig. 2a, d, e). Anti-inflammatory activities of PPARs were extensively described in diverse systems, including the CNS. Therefore, we investigated microglial activation status in brain sections by using the activation marker Ibal. The quantification of the Iba1-covered area in the cortex showed a reduction of $43 \%$ in mice treated with GFT1803 at $1 \mathrm{mg} / \mathrm{kg}$ and a reduction of $57 \%$ in mice treated with GFT 1803 at $10 \mathrm{mg} / \mathrm{kg}$, but no effect for mice treated with pioglitazone (Fig. 2f, g). Similarly, the number of microglia per section was reduced in both cortex ( $42 \%$ for $1 \mathrm{mg} / \mathrm{kg}$ and $57 \%$ for $10 \mathrm{mg} / \mathrm{kg}$ ) and to a lesser extent in hippocampus ( $38 \%$ for $10 \mathrm{mg} / \mathrm{kg}$ ), again with no effect in the pioglitazone treatment group (Fig. 2h, i).

Western blot analysis of RIPA-extracted forebrain homogenates revealed no changes in APP expression (Fig. $3 \mathrm{a}-\mathrm{c}$ ), nor in the $\alpha$ - and $\beta$-CTFs to APP ratio, suggesting unchanged APP processing (Fig. 3a, d, e). In contrary, we observed a reduction of $\mathrm{A} \beta$ in the FA and SDS fractions (Fig. 3a, f, g), which confirmed the ELISA results. The expression of the glial fibrillary acidic protein (GFAP), which is considered as an astrocytic activation marker and therefore indicator of glial inflammation, was found to be increased in APP/PS1 animals as compared to wild-type mice, whereas treatment with either
GFT1803 or pioglitazone brought GFAP levels back to the level observed in wild-type mice (Fig. 3a, h). Since ApoE is implicated in $\mathrm{A} \beta$ removal $[30,31]$, we also tested if its expression was modulated in brains of treated mice, but ApoE expression remained stable (Fig. 3a, i). Interestingly, we observed that treatment with GFT1803 but not with pioglitazone induced the expression of the insulin-degrading enzyme (IDE), a key protease, able to degrade $A \beta$ (Fig. $3 a, j$ ).

These data demonstrate that in APP/PS1 mice, the effect of GFT1803 on diverse AD pathology parameters was quantitatively and/or qualitatively superior as compared to pioglitazone. More specifically, GFT1803 performed better in reducing both highly insoluble (FA pool) and to a smaller extent moderately insoluble (SDS pool) A $\beta$ peptides and also curbed microglial activation, which was not obtained by pioglitazone treatment at the applied dosage.

\section{GFT1803 Improves Spatial Learning and Memory in APP/PS1 Mice}

We used the Morris water maze paradigm to evaluate the effect of GFT1803 treatment on hippocampal memory formation. As expected, wild-type mice performed best according to latency and distance, whereas APP/PS1 mice showed impairments for both parameters (204 and $183 \%$ area under the curve (AUC) increase for latency and distance, respectively) (Fig. 4a-e). Treatment with both doses of GFT1803 reduced latency ( $25 \%$ for $1 \mathrm{mg} / \mathrm{kg}$ and $34 \%$ for $10 \mathrm{mg} / \mathrm{kg}$ vs. APP/ PS1; AUC) as well as the distance swum (34 \% for $1 \mathrm{mg} / \mathrm{kg}$ and $33 \%$ for $10 \mathrm{mg} / \mathrm{kg}$ vs. APP/PS1; AUC). Pioglitazone in turn improved these parameters only in tendency. The probe trial demonstrated that none of the groups failed to form spatial memory (Fig. 4f). This indicates that GFT1803 improves spatial learning and/or memory retention in APP/PS1 mice.

Next, we assessed context-dependent habituation to a novel environment in the open field. APP/PS1 mice showed higher activity and less habituation than wild-type mice. Importantly, mice treated with $10 \mathrm{mg} / \mathrm{kg}$ GFT1803 habituated faster and more completely than APP/PS1 mice, suggesting improved contextual learning (Fig. 4g). We did not observe effects treating with the lower dose of GFT1803 or pioglitazone. 
Fig. 1 Experimental procedures, pharmacokinetics, and $\mathrm{A} \beta$ ELISA. a Scheme of the experimental procedures. Mice were treated from the age of 4-6 months with either GFT1803 or pioglitazone. At the beginning of month 6 , mice were tested in the Morris water maze and in the open field paradigm for a total of 9 days. Drug treatment was continued during this time. Finally, mice were sacrificed and brains were subjected to histological analysis.

b Pharmacokinetics of GFT1803 and pioglitazone in Swiss mice.

Compounds were administered by oral gavage (GFT1803 at 1 and $10 \mathrm{mg} / \mathrm{kg}$; pioglitazone at $30 \mathrm{mg} / \mathrm{kg}$ ) and their brain concentrations were measured throughout $24 \mathrm{~h}$ (mean $\pm \mathrm{SD}$ ). c Determination of the area under the curve $(A U C)$ values after $24 \mathrm{~h}$ of long exposure to the drugs. d Quantification of RIPA-soluble A $\beta 38,40$, and 42 from APP/PS1 mice treated with placebo (control), $1 \mathrm{mg} / \mathrm{kg}$ GFT1803, $10 \mathrm{mg} / \mathrm{kg}$ GFT1803, or $50 \mathrm{mg} / \mathrm{kg}$ pioglitazone (pio) by multiplex ELISA. A $\beta 38$ could not be detected in this fraction. e Same as (d) but for SDS-soluble A $\beta 38$, 40, and 42. f Same as (d) but for formic acid-soluble $\mathrm{A} \beta 38,40$, and 42 (mean of $n=11$ for control, $n=9$ for pio, $n=12$ for $1 \mathrm{mg} / \mathrm{kg}$ GFT1803, and $n=11$ for $10 \mathrm{mg} / \mathrm{kg}$ GFT1803 \pm SEM; one-way ANOVA, Tukey post hoc test; ${ }^{*} p<0.05,{ }^{* *} p<0.01$, $* * * p<0.001$ ) a
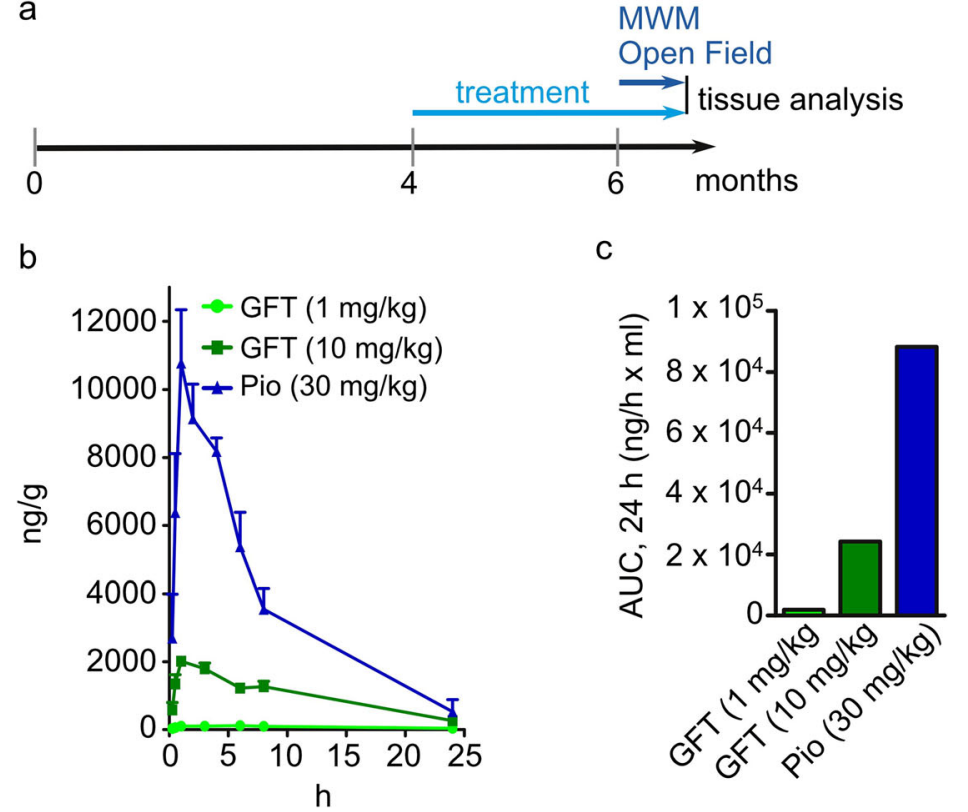

d
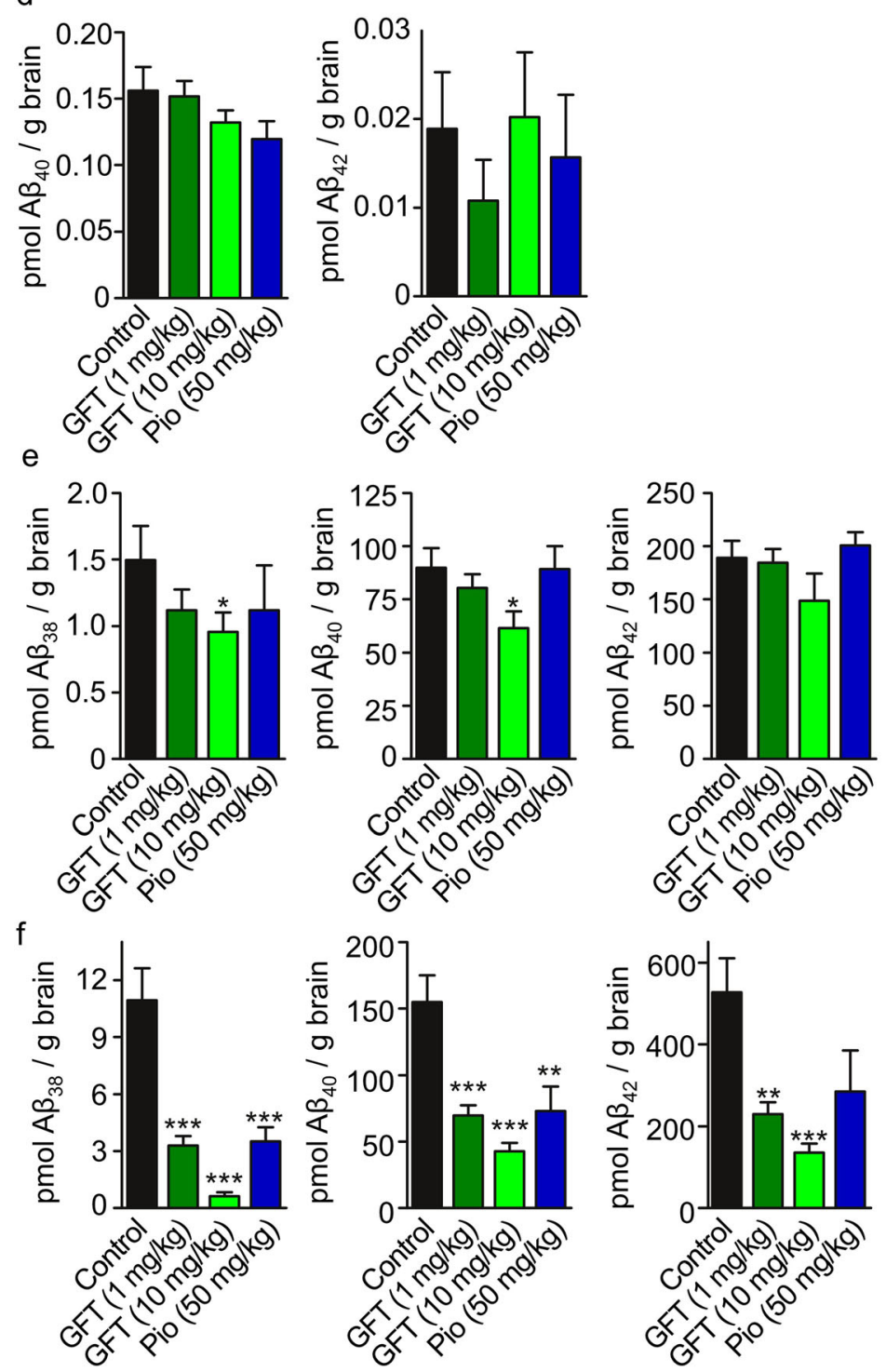
Table 2 Values that correspond to the mean plasma and brain 24-h AUC (ng/h*ml)

\begin{tabular}{llll}
\hline & AUC $[24 \mathrm{~h}]$ Brain $\left(\mathrm{ng} \times \mathrm{h}^{-1} \times \mathrm{ml}^{-1}\right)$ & AUC $[24 \mathrm{~h}]$ Plasma $\left(\mathrm{ng} \times \mathrm{h}^{-1} \times \mathrm{ml}^{-1}\right)$ & Brain $/$ plasma ratio \\
\hline GFT1803 $(1 \mathrm{mg} / \mathrm{kg})$ & 1,921 & 6,065 & 0.32 \\
GFT1803 $(10 \mathrm{mg} / \mathrm{kg})$ & 24,249 & 88,854 & 0.27 \\
Pio $(30 \mathrm{mg} / \mathrm{kg})$ & 88,112 & 252,551 & 0.35 \\
\hline
\end{tabular}

In relative numbers, the central exposure to pioglitazone $(30 \mathrm{mg} / \mathrm{kg})$ was roughly 50 times higher as compared to $\mathrm{GFT} 1803(1 \mathrm{mg} / \mathrm{kg})$ and roughly 3.57 times higher as compared to GFT1803 $(10 \mathrm{mg} / \mathrm{kg})$. Both compounds showed similar brain/plasma partitioning ratio of $0.27-0.35$ (AUC area under the curve)

\section{Discussion}

In this study, we provide a comprehensive analysis of the new pan-PPAR agonist GFT1803 for its impact on receptor activation, plaque burden, neuroinflammation, and spatial memory in a murine model of Alzheimer's disease (AD). Previous studies have shown beneficial effects of PPAR $\gamma$ activation in several animal models of neurological disease [10], including cerebral ischemia [23], multiple sclerosis [32], Parkinson's disease [33], and AD [12]. These experimental studies primarily used agonists of the thiazolidinedione class of antidiabetic drugs (TZDs), which were developed for the treatment of non-
Fig. 2 Histological analysis. a Brain section of APP/PS1 mice treated with placebo (control), $1 \mathrm{mg} / \mathrm{kg}$ GFT1803, $10 \mathrm{mg} / \mathrm{kg}$ GFT1803, or $50 \mathrm{mg} / \mathrm{kg}$ pioglitazone (pio) were stained with the amyloid dye methoxyXO4 followed by immunostaining using antibodies IC16 against A $\beta$ and the antibody anti-Ibal to detect microglia. b Quantification of methoxy-XO4-positive plaques in the cortex and $\mathbf{c}$ in the hippocampus. d Determination of $\mathrm{A} \beta$-covered area using antibody IC16 in the cortex and $\mathbf{e}$ in the hippocampus. $\mathbf{f}$ Determination of Ibal-covered area using antibody anti-Ibal in the cortex and $\mathbf{g}$ in the hippocampus. h Quantification of Iba1-positive microglia in the cortex and $\mathbf{i}$ in the hippocampus (mean of $n=5$ for control, $n=5$ for pio, $n=6$ for $1 \mathrm{mg} / \mathrm{kg}$ GFT1803, and $n=7$ for $10 \mathrm{mg} / \mathrm{kg}$ GFT1803 \pm SEM; one-way ANOVA, Tukey post hoc test; ${ }^{*} p<0.05,{ }^{* *} p<0.01$, $* * * p<0.001)$ a

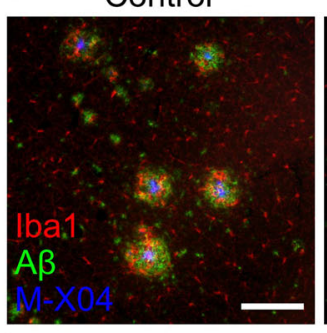

b
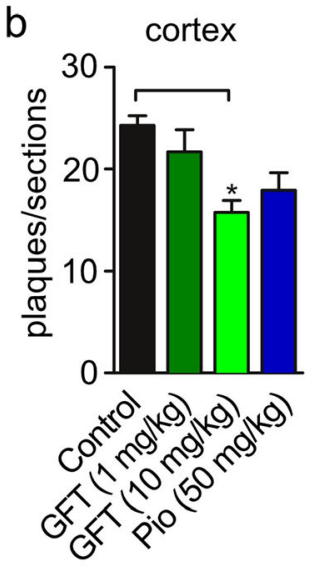

f

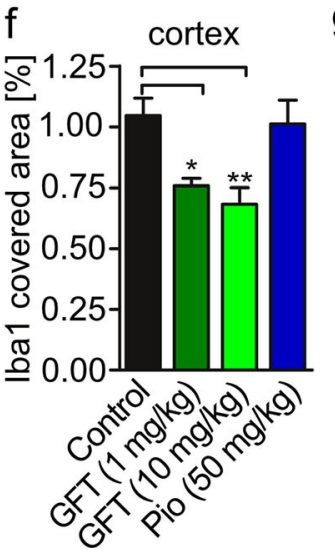

GFT (1 mg/kg)

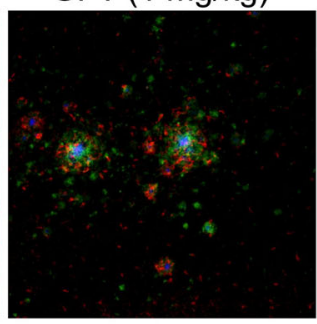

C hippocampus

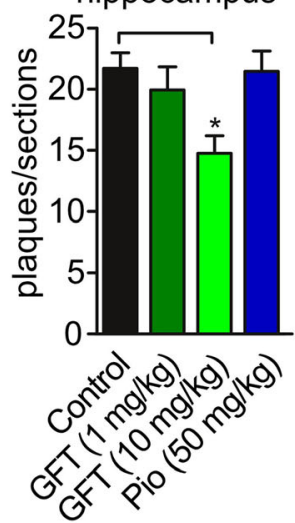

9 hippocampus $\mathrm{h}$

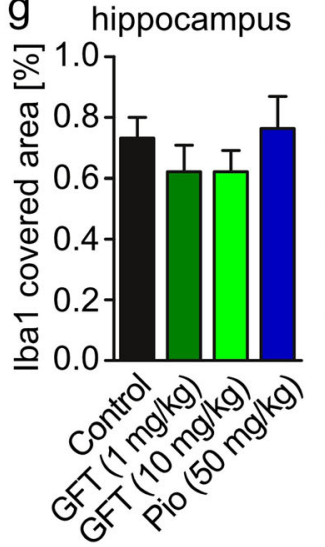

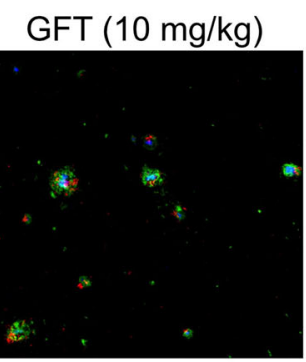

cortex
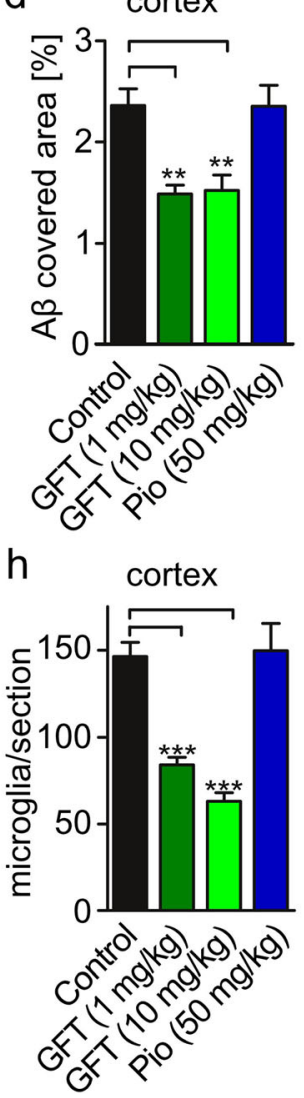

Pio $(50 \mathrm{mg} / \mathrm{kg})$

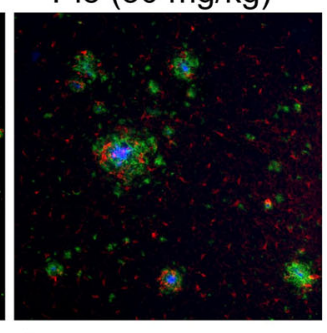

hippocampus

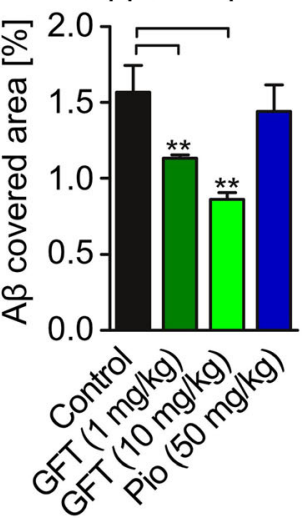

i hippocampus

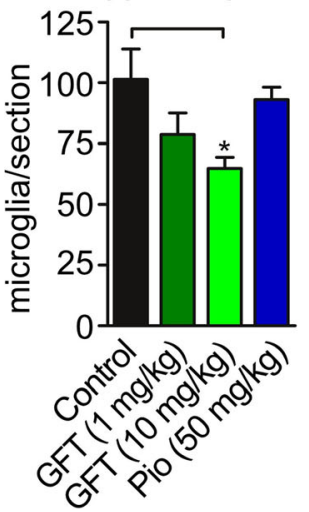


Fig. 3 Biochemical analysis. a Immunoblot analysis of APP and APP-CTF in forebrain samples using antibody CT15, APP and $A \beta$ using antibody 6E10, GFAP, IDE, ApoE, and tubulin. Densiometric quantification of $\mathbf{b}$ APP using $\mathrm{CT} 15, \mathbf{c}$ of APP/sAPP $\alpha$ using antibody $6 \mathrm{E} 10, \mathbf{d} \alpha-\mathrm{CTF} / \mathrm{APP}$ using antibody CT15, e $\beta-\mathrm{CTF} /$ APP using antibody $\mathrm{CT} 15, \mathbf{f} \mathrm{A} \beta$ in the SDS fraction, $\mathbf{g} A \beta$ in the FA fraction, $\mathbf{h}$ GFAP $\mathbf{i}$ of ApoE, $\mathbf{j}$ and of IDE (b-g are mean of $n=5 \pm$ SEM, one-way ANOVA, Tukey post hoc test; ${ }^{*} p<0.05$, $\left.{ }^{* *} p<0.01, * * * p<0.001\right)$

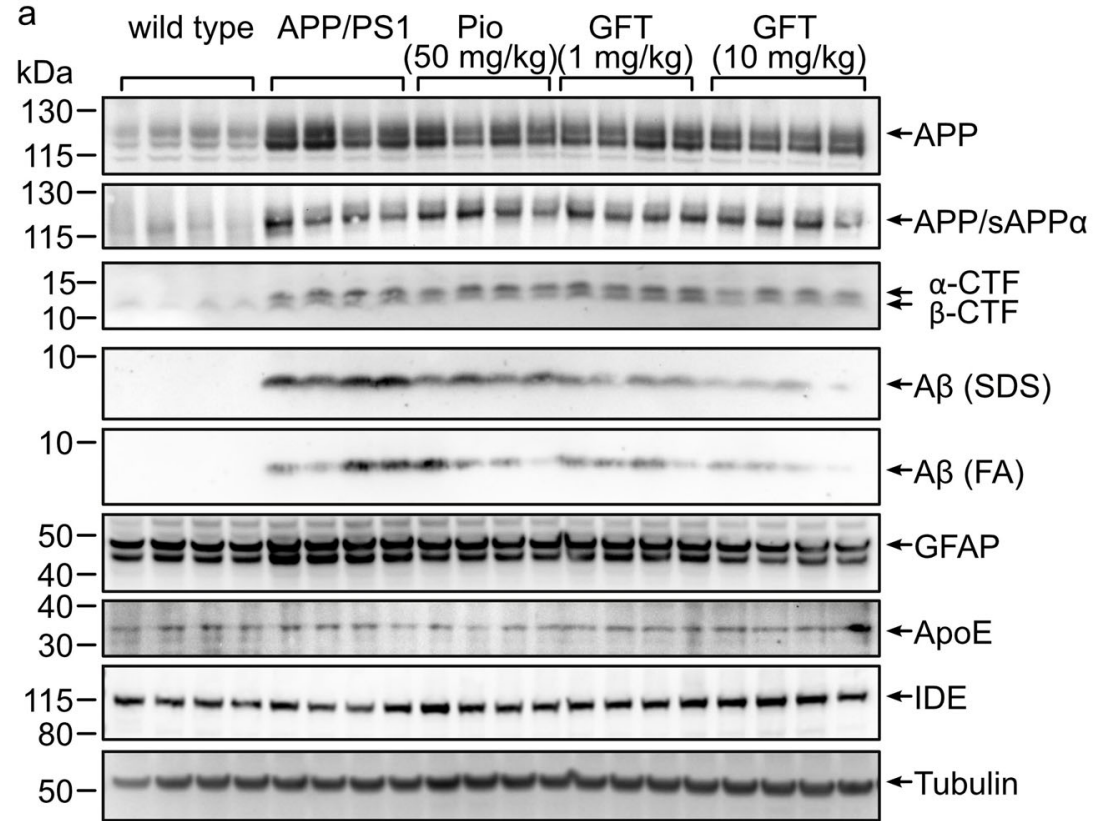

b

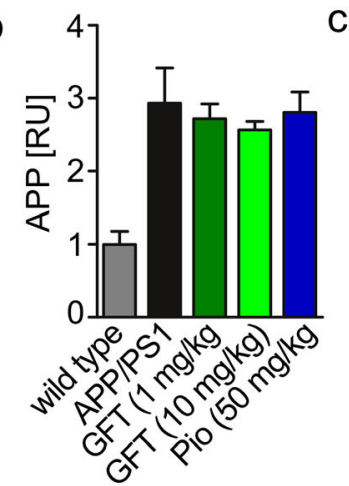

e

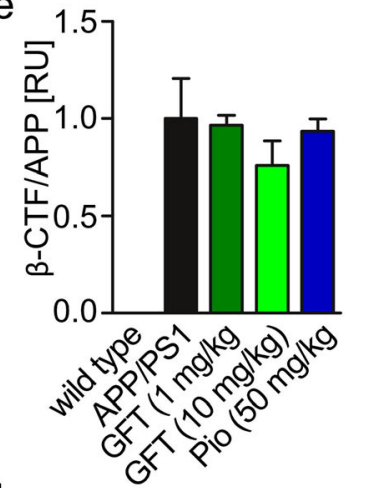

h

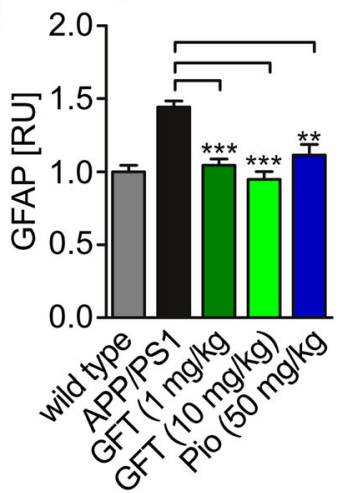

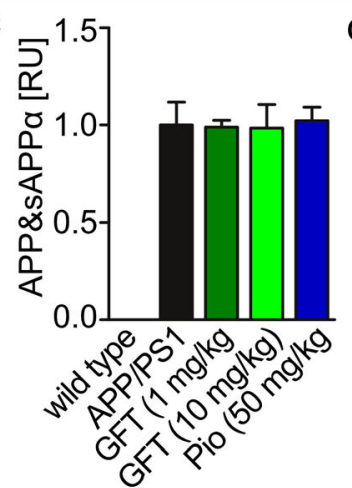
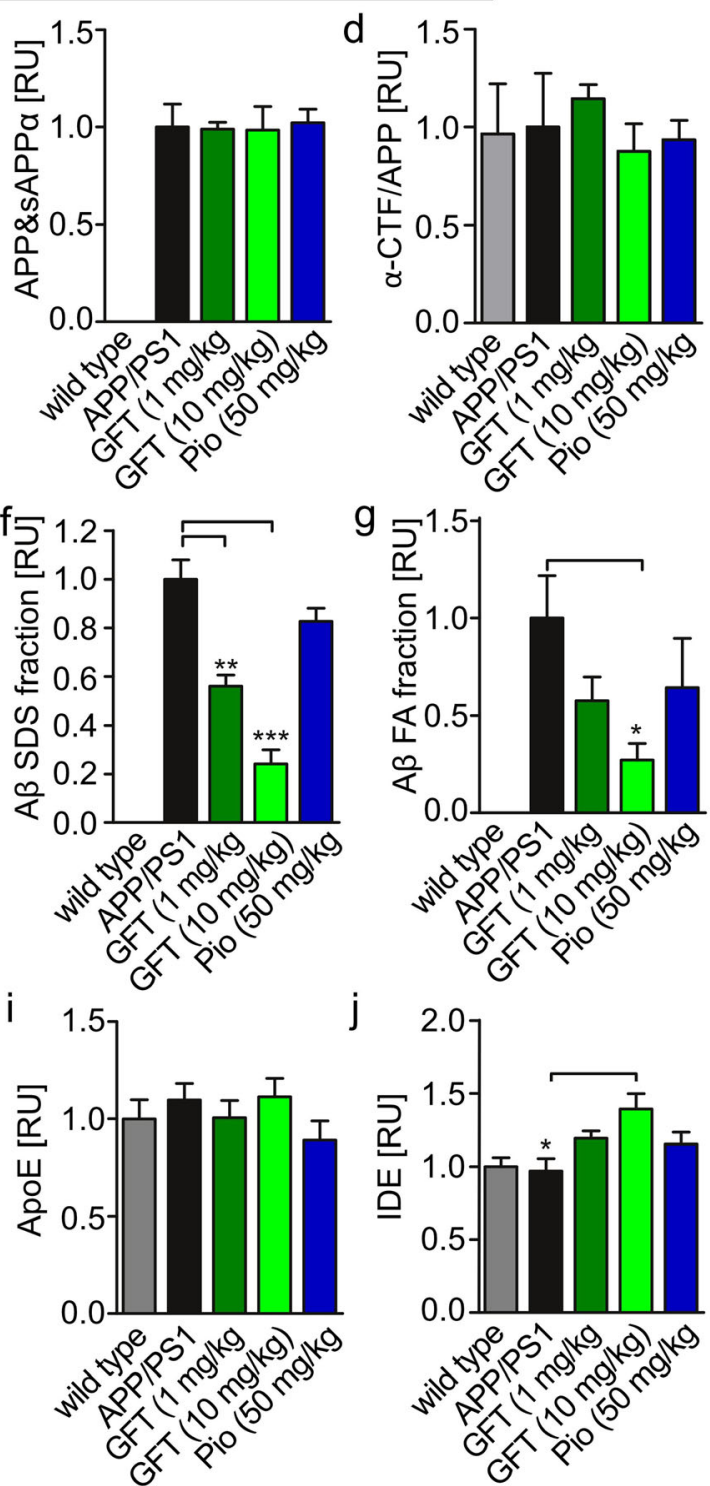


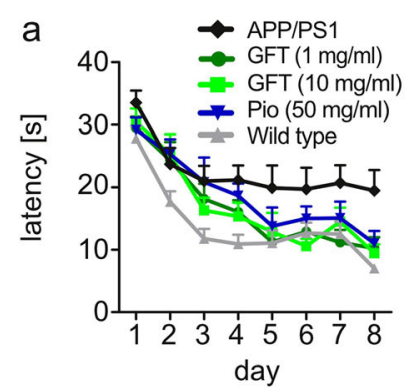

e
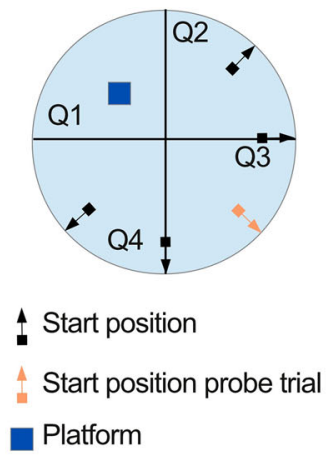

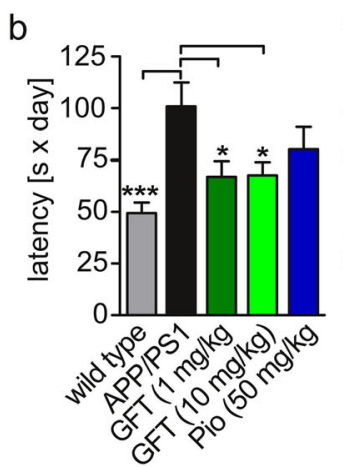

f

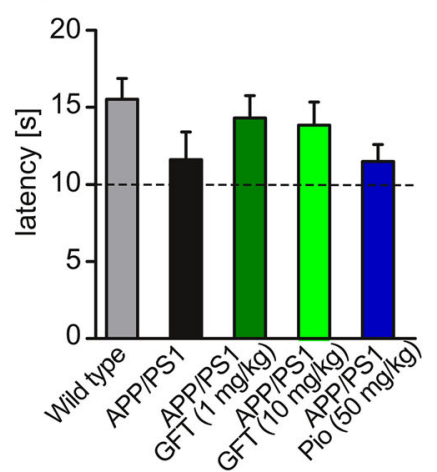

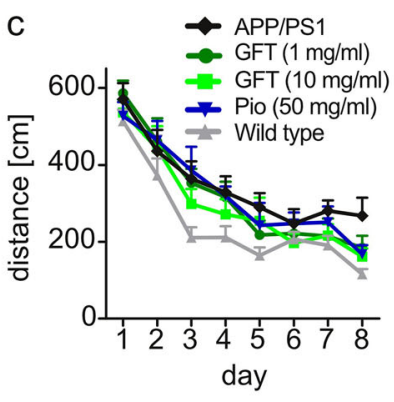
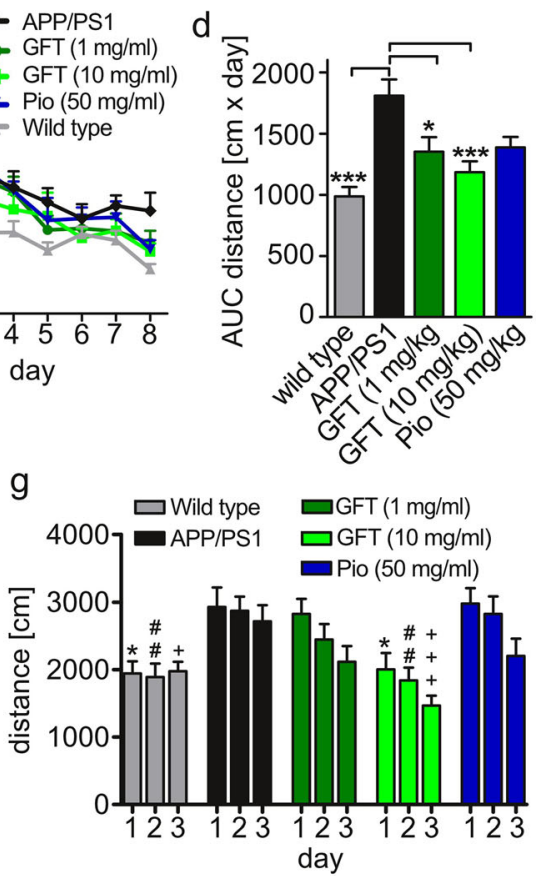

Fig. 4 Behavioral analysis. Spatial memory learning of APP/PS1 mice treated with placebo (control), $1 \mathrm{mg} / \mathrm{kg}$ GFT1803, $10 \mathrm{mg} / \mathrm{kg}$ GFT1803, or $50 \mathrm{mg} / \mathrm{kg}$ pioglitazone (pio) in the Morris water maze. a Time needed to reach the hidden platform (latency in seconds). b Integrated time to reach the platform (area under the curve). $\mathbf{c}$ Distance traveled (in centimeters). $\mathbf{d}$ Integrated distance traveled (area under the curve). e Setup of the Morris water maze ( $Q 1-4$ quadrant 1-4). f Mice were tested 1 day after the last trial day for $30 \mathrm{~s}$ in the absence of the platform. The time in the quadrants was measured and averaged for quadrants $2-4$ (Q1-4 av.) (mean of $n=11$ for control, $n=9$ for pio, $n=12$ for $1 \mathrm{mg} / \mathrm{kg}$ GFT1803, and $n=11$ for $10 \mathrm{mg} / \mathrm{kg}$ GFT1803 \pm SEM, Student's $t$ test, $\left.{ }^{* *} p<0.01,{ }^{* * *} p<0.001\right)$. g Distance traveled (in centimeters) in the open field assessment (mean of $n=11$ for control, $n=9$ for pio, $n=12$ for $1 \mathrm{mg} / \mathrm{kg} \mathrm{GFT} 1803$, and $n=11$ for $10 \mathrm{mg} / \mathrm{kg}$ GFT1803 \pm SEM; one-way ANOVA, Tukey post hoc test; $\left.{ }^{*} p<0.05,{ }^{* *} p<0.01, * * * p<0.001\right)$ insulin dependent type 2 diabetes. Since TZDs have recently come under scrutiny for their potential cardiovascular side effects, some of these drugs are not longer considered as possible interventional therapeutics [34]. Positive reports of agonists activating other PPAR isoforms, which reduced $A \beta$ plaque burden [22] and concomitant neuroinflammation [35] lead to the development of novel pan-PPAR ligands. Current characterization of these substances suggests they may demonstrate better benefit/risk ratios due to a balanced activation of all three PPAR isoforms, while at the same time keeping the positive properties reported for single receptor activation.

In the present study, preventive treatment of APP/PS1 mice with GFT1803 was initiated well before the onset of plaque deposition and strikingly suppressed $A \beta$ deposition at later stages. Analyzing brain homogenates, the strongest reduction was observed in the extremely insoluble formic acid fraction of $A \beta$. This finding suggests that either the formation of $A \beta$ deposits were efficiently prevented or the removal was specifically stimulated. The latter hypothesis is supported by recent findings showing that PPAR activation increased microglial clearance through CD36-dependent phagocytosis [36]. Given recent evidence that reduced $A \beta$ clearance accounts for the majority of AD cases of sporadic nature [37], increasing microglial clearance through pan-PPAR modulation may offer a novel therapeutic strategy. Immunohistological analysis of the effect of pioglitazone on $A \beta$ deposition revealed minor changes, whereas the ELISA results show a strong decrease in the FA fraction. This might be due to the fact that both methods do no describe the exact same pool of $A \beta$.

In $\mathrm{AD}, \mathrm{A} \beta$ deposition and neuronal demise activate microglia through several surface molecules including toll-like receptors [38], which subsequently leads to the production and release of proinflammatory molecules including cytokines, chemokines, nitric oxide, and prostaglandins. This acute and sterile inflammatory action may initially serve the attempt to maintain cerebral homeostasis and increase clearance capacity of microglia. While usually this type of inflammation rapidly resolves upon pathogen removal, ongoing deposition of $\mathrm{A} \beta$ does not allow for resolution but leads to a chronic type of cerebral inflammation. Furthermore, a chronic proinflammatory environment is able to upregulate neuronal BACE1 thereby further fueling APP processing and A $\beta$ generation $[22,39]$. Likewise, inflammation-driven induction of NOS2 which goes along with massive production of nitric oxide induces the nitration-induced aggregation of $A \beta$ in senile plaques [40]. 
Based on the overall detrimental action of chronic neuroinflammation, inhibitory interventions are sought. Preventive GFT1803 treatment of APP/PS1 mice reduced microglial immunoreactivity, suggesting suppression of the neuroinflammatory component in this model. Most likely, this anti-inflammatory action is due to activation of all three PPAR isoforms and not mediated by a single receptor, since all PPARs have been shown to exert anti-inflammatory action. Thus, PPAR $\gamma$ activation results in strong suppression of inflammation by transcriptional transrepression of NFKB [41]. This anti-inflammatory action of PPAR $\gamma$ ligands was shown to be neuroprotective in several experimental models of neuroimmunological and neurodegenerative disease $[12,23,32,33]$. Likewise, the PPAR $\alpha$ agonist fenofibrate protected neurons and axons against micro- and astrogliaderived nitric oxide-mediated toxicity in vitro and inhibited the secretion of the proinflammatory cytokines IL-1 $\beta$, TNF- $\alpha$, IL-6, and IL-12 p40 34, 35. Additionally, PPAR $\alpha$ induces transcription of genes of the $\beta$ - and $\omega$-oxidation pathways that neutralize and degrade LTB4, a powerful chemotactic inflammatory eicosanoid, to regulate the inflammatory response [42]. Administration of GW0742, a potent PPAR $\delta$-selective agonist, significantly reduced amyloid plaque burden in the subiculum of $5 \mathrm{xFAD}$ mice, which was associated with decreased glial activation and increased expression of neprilysin, an amyloid-degrading, microgliaderived enzyme [22]. The antioxidant and anti-inflammatory actions of PPAR $\delta$ agonists have been observed in a variety of cell types, including astrocytes and microglia. In particular, PPAR $\delta$ can activate transcription of antioxidant genes, including catalase and superoxide dismutase [43, 44]. The improved learning and memory phenotype found in response to the treatment with GFT1803 is likely to arise of a combination of the above described $A \beta$-reducing and anti-inflammatory effects, as both, $A \beta$ and inflammatory molecules have been shown to suppress memory relevant neurophysiological processes such as hippocampal long-term potentiation $[45,46]$. In most of the parameters analyzed in this study, GFT1803 was superior when compared to treatment with the TZD pioglitazone at drug concentrations previously investigated in models of neurodegeneration.

Currently, the pioglitazone is tested in a phase III study to evaluate the efficacy of a long-term treatment with low-dose pioglitazone in delaying the onset of MCI in cognitively normal individuals at high risk. Even so, we did not detect strong effects in our mouse model, long-term, low-dose treatment with pioglitazone might still be effective.

Even so, we cannot rule out that the superior efficacy of GFT1803 was caused by yet non-described off-target effects, unrelated to the activation of PPARs; one might consider that targeting all three PPAR isoforms may represent a successful strategy to suppress cerebral amyloidosis and chronic inflammation. The data presented here identify GFT1803 as a highly efficient PPAR agonist, which prevents the development of pathological and behavioral hallmarks of AD in the AP/PS1 mouse model when given from early time points on. Further studies have to prove now whether these promising data hold true in human $\mathrm{AD}$.

Acknowledgments The E7 antibody developed by M. Klymkowsky was obtained from the Developmental Studies Hybridoma Bank. This study was supported by the Deutsche Forschungsgemeinschaft (KFO177, TP4) to MTH and by grants of the INMiND project of the European Union. MTH is member of the DFG Cluster of Excellence ImmunoSensation.

Conflict of Interest Sakina Sayah-Jeanne, Mathieu Dubernet, Robert Walczak, and Dean W. Hum are employees of GENFIT SA. This study was in part sponsored by GENFIT SA.

Open Access This article is distributed under the terms of the Creative Commons Attribution License which permits any use, distribution, and reproduction in any medium, provided the original author(s) and the source are credited.

\section{References}

1. Querfurth HW, LaFerla FM (2010) Alzheimer's disease. N Engl J Med 362:329-344. doi:10.1056/NEJMra0909142

2. Jack CR Jr, Knopman DS, Jagust WJ et al (2013) Tracking pathophysiological processes in Alzheimer's disease: an updated hypothetical model of dynamic biomarkers. Lancet Neurol 12:207-216. doi:10. 1016/S1474-4422(12)70291-0

3. Palop JJ, Mucke L (2010) Amyloid- $\beta$ induced neuronal dysfunction in Alzheimer's disease: from synapses toward neural networks. Nat Neurosci 13:812-818. doi:10.1038/nn.2583

4. Benilova I, Karran E, De Strooper B (2012) The toxic A $\beta$ oligomer and Alzheimer's disease: an emperor in need of clothes. Nat Neurosci 15:349-357. doi:10.1038/nn.3028

5. In t' Veld BA, Ruitenberg A, Hofman A et al (2001) Nonsteroidal antiinflammatory drugs and the risk of Alzheimer's disease. N Engl J Med 345:1515-1521. doi:10.1056/NEJMoa010178

6. Heneka MT, Landreth GE, Feinstein DL (2001) Role for peroxisome proliferator-activated receptor-gamma in Alzheimer's disease. Ann Neurol 49:276

7. Lehmann JM, Lenhard JM, Oliver BB et al (1997) Peroxisome proliferator-activated receptors alpha and gamma are activated by indomethacin and other non-steroidal anti-inflammatory drugs. J Biol Chem 272:3406-3410

8. Jiang C, Ting AT, Seed B (1998) PPAR-gamma agonists inhibit production of monocyte inflammatory cytokines. Nature 391:8286. doi: $10.1038 / 34184$

9. Ricote M, Li AC, Willson TM et al (1998) The peroxisome proliferator-activated receptor-gamma is a negative regulator of macrophage activation. Nature 391:79-82. doi:10.1038/34178

10. Heneka MT, Landreth GE (2007) PPARs in the brain. Biochim Biophys Acta 1771:1031-1045. doi:10.1016/j.bbalip.2007.04.016

11. Yan Q, Zhang J, Liu H et al (2003) Anti-inflammatory drug therapy alters beta-amyloid processing and deposition in an animal model of Alzheimer's disease. J Neurosci Off J Soc Neurosci 23:7504-7509

12. Heneka MT, Sastre M, Dumitrescu-Ozimek L et al (2005) Acute treatment with the PPARgamma agonist pioglitazone and ibuprofen reduces glial inflammation and Abeta1-42 levels in APPV717I 
transgenic mice. Brain J Neurol 128:1442-1453. doi:10.1093/brain/ awh452

13. Combs CK, Johnson DE, Karlo JC et al (2000) Inflammatory mechanisms in Alzheimer's disease: inhibition of beta-amyloid-stimulated proinflammatory responses and neurotoxicity by PPARgamma agonists. J Neurosci Off J Soc Neurosci 20:558-567

14. Kim EJ, Kwon KJ, Park JY et al (2002) Effects of peroxisome proliferator-activated receptor agonists on LPS-induced neuronal death in mixed cortical neurons: associated with iNOS and COX-2. Brain Res 941:1-10

15. Luna-Medina R, Cortes-Canteli M, Alonso M et al (2005) Regulation of inflammatory response in neural cells in vitro by thiadiazolidinones derivatives through peroxisome proliferator-activated receptor gamma activation. J Biol Chem 280:21453-21462. doi:10. 1074/jbc.M414390200

16. Sastre M, Dewachter I, Landreth GE et al (2003) Nonsteroidal antiinflammatory drugs and peroxisome proliferator-activated receptorgamma agonists modulate immunostimulated processing of amyloid precursor protein through regulation of beta-secretase. J Neurosci Off J Soc Neurosci 23:9796-9804

17. Sastre M, Dewachter I, Rossner S et al (2006) Nonsteroidal antiinflammatory drugs repress beta-secretase gene promoter activity by the activation of PPARgamma. Proc Natl Acad Sci U S A 103:443448. doi:10.1073/pnas.0503839103

18. De la Monte SM, Tong M, Lester-Coll N et al (2006) Therapeutic rescue of neurodegeneration in experimental type 3 diabetes: relevance to Alzheimer's disease. J Alzheimers Dis JAD 10:89-109

19. Hiukka A, Maranghi M, Matikainen N, Taskinen M-R (2010) PPARalpha: an emerging therapeutic target in diabetic microvascular damage. Nat Rev Endocrinol 6:454-463. doi:10.1038/ nrendo.2010.89

20. Yin K-J, Deng Z, Hamblin M et al (2011) Vascular PPAR $\delta$ protects against stroke-induced brain injury. Arterioscler Thromb Vasc Biol 31:574-581. doi:10.1161/ATVBAHA.110.221267

21. Polak PE, Kalinin S, Dello Russo C et al (2005) Protective effects of a peroxisome proliferator-activated receptor-beta/delta agonist in experimental autoimmune encephalomyelitis. J Neuroimmunol 168: 65-75. doi:10.1016/j.jneuroim.2005.07.006

22. Kalinin S, Richardson JC, Feinstein DL (2009) A PPARdelta agonist reduces amyloid burden and brain inflammation in a transgenic mouse model of Alzheimer's disease. Curr Alzheimer Res 6:431-437

23. Iwashita A, Muramatsu Y, Yamazaki T et al (2007) Neuroprotective efficacy of the peroxisome proliferator-activated receptor deltaselective agonists in vitro and in vivo. J Pharmacol Exp Ther 320: 1087-1096. doi:10.1124/jpet.106.115758

24. Paterniti I, Esposito E, Mazzon E et al (2010) Evidence for the role of peroxisome proliferator-activated receptor-beta/delta in the development of spinal cord injury. J Pharmacol Exp Ther 333:465-477. doi: 10.1124/jpet.110.165605

25. Jankowsky JL, Slunt HH, Ratovitski T et al (2001) Co-expression of multiple transgenes in mouse CNS: a comparison of strategies. Biomol Eng 17:157-165

26. Jardanhazi-Kurutz D, Kummer MP, Terwel D et al (2010) Induced LC degeneration in APP/PS1 transgenic mice accelerates early cerebral amyloidosis and cognitive deficits. Neurochem Int 57:375-382. doi:10.1016/j.neuint.2010.02.001

27. Jäger S, Leuchtenberger S, Martin A et al (2009) Alpha-secretase mediated conversion of the Amyloid Precursor Protein derived membrane stub C99 to C83 limits Abeta generation. J Neurochem. doi:10. 1111/j.1471-4159.2009.06420.x

28. Klunk WE, Bacskai BJ, Mathis CA et al (2002) Imaging Abeta plaques in living transgenic mice with multiphoton microscopy and methoxy-X04, a systemically administered Congo red derivative. J Neuropathol Exp Neurol 61:797-805

29. Wahle T, Thal DR, Sastre M et al (2006) GGA1 is expressed in the human brain and affects the generation of amyloid beta-peptide. J
Neurosci Off J Soc Neurosci 26:12838-12846. doi:10.1523/ JNEUROSCI.1982-06.2006

30. Terwel D, Steffensen KR, Verghese PB et al (2011) Critical role of astroglial apolipoprotein $\mathrm{E}$ and liver $\mathrm{X}$ receptor- $\alpha$ expression for microglial A $\beta$ phagocytosis. J Neurosci Off J Soc Neurosci 31: 7049-7059. doi:10.1523/JNEUROSCI.6546-10.2011

31. Cramer PE, Cirrito JR, Wesson DW et al (2012) ApoE-directed therapeutics rapidly clear $\beta$-amyloid and reverse deficits in $\mathrm{AD}$ mouse models. Science 335:1503-1506. doi:10.1126/science. 1217697

32. Diab A, Deng C, Smith JD et al (1950) (2002) Peroxisome proliferatoractivated receptor-gamma agonist 15-deoxy-Delta(12,14)-prostaglandin $\mathrm{J}(2)$ ameliorates experimental autoimmune encephalomyelitis. $\mathrm{J}$ Immunol Baltim Md 168:2508-2515

33. Dehmer T, Heneka MT, Sastre M et al (2004) Protection by pioglitazone in the MPTP model of Parkinson's disease correlates with I kappa B alpha induction and block of NF kappa B and iNOS activation. J Neurochem 88:494-501

34. Hiatt WR, Kaul S, Smith RJ (2013) The cardiovascular safety of diabetes drugs - insights from the rosiglitazone experience. N Engl J Med 369:1285-1287. doi:10.1056/NEJMp1309610

35. Combs CK, Bates P, Karlo JC, Landreth GE (2001) Regulation of beta-amyloid stimulated proinflammatory responses by peroxisome proliferator-activated receptor alpha. Neurochem Int 39:449-457

36. Yamanaka $M$, Ishikawa $T$, Griep A et al (2012) PPAR $\gamma / R X R \alpha-$ induced and CD36-mediated microglial amyloid- $\beta$ phagocytosis results in cognitive improvement in amyloid precursor protein/ presenilin 1 mice. J Neurosci Off J Soc Neurosci 32:17321-17331. doi:10.1523/JNEUROSCI.1569-12.2012

37. Mawuenyega KG, Sigurdson W, Ovod V et al (2010) Decreased clearance of CNS $\beta$-amyloid in Alzheimer's disease. Science 330: 1774. doi:10.1126/science. 1197623

38. Reed-Geaghan EG, Savage JC, Hise AG, Landreth GE (2009) $\mathrm{CD} 14$ and toll-like receptors 2 and 4 are required for fibrillar A $\{$ beta\}-stimulated microglial activation. J Neurosci Off J Soc Neurosci 29:11982-11992. doi:10.1523/JNEUROSCI.3158-09. 2009

39. Heneka MT, Sastre M, Dumitrescu-Ozimek L et al (2005) Focal glial activation coincides with increased BACE1 activation and precedes amyloid plaque deposition in APP[V717I] transgenic mice. J Neuroinflammation 2:22. doi:10.1186/1742-2094-2-22

40. Kummer MP, Hermes M, Delekarte A et al (2011) Nitration of tyrosine 10 critically enhances amyloid $\beta$ aggregation and plaque formation. Neuron 71:833-844. doi:10.1016/j.neuron.2011.07.001

41. Daynes RA, Jones DC (2002) Emerging roles of PPARs in inflammation and immunity. Nat Rev Immunol 2:748-759. doi:10.1038/ nri912

42. Devchand PR, Keller H, Peters JM et al (1996) The PPARalphaleukotriene B4 pathway to inflammation control. Nature 384:39-43. doi:10.1038/384039a0

43. Pesant M, Sueur S, Dutartre P et al (2006) Peroxisome proliferatoractivated receptor delta (PPARdelta) activation protects $\mathrm{H} 9 \mathrm{c} 2$ cardiomyoblasts from oxidative stress-induced apoptosis. Cardiovasc Res 69:440-449. doi:10.1016/j.cardiores.2005.10.019

44. D' Uscio LV, Das P, Santhanam AVR et al (2012) Activation of PPAR $\delta$ prevents endothelial dysfunction induced by overexpression of amyloid- $\beta$ precursor protein. Cardiovasc Res 96:504-512. doi:10. $1093 / \mathrm{cvr} / \mathrm{cvs} 266$

45. Nalbantoglu J, Tirado-Santiago G, Lahsaini A et al (1997) Impaired learning and LTP in mice expressing the carboxy terminus of the Alzheimer amyloid precursor protein. Nature 387:500-505. doi:10. 1038/387500a0

46. Walsh DM, Klyubin I, Fadeeva JV et al (2002) Naturally secreted oligomers of amyloid beta protein potently inhibit hippocampal long-term potentiation in vivo. Nature 416:535539. doi:10.1038/416535a 